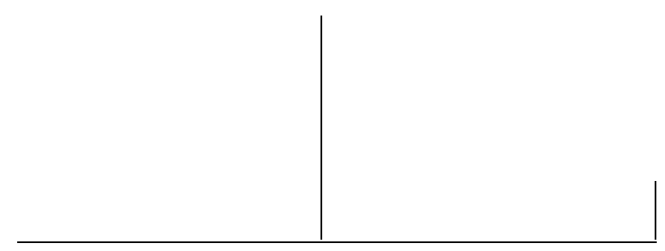

Rev. Latinoam. Psicopat. Fund., VI, 3, 11-29

\title{
Fenômeno, estrutura, sintoma e clínica: a droga
}

\author{
Sonia Alberti \\ Clara Lúcia Inem \\ Flavia Corpas Rangel
}

Partindo de uma leitura que se baseia em quatro autores brasileiros, este trabalho problematiza e verifica posições teóricas acerca do fenômeno toxicomaníaco e levanta a hipótese de que é possível, com o discurso do analista, em certo contexto e a partir de certas condições, apontar a toxicomania como equivalente ao sintoma no discurso da histérica, o que abre vias para a construção de uma clínica em que prevaleça a aposta no desejo do analista.

Ao retomar as referências freudianas quanto à equivalência da droga com o discurso religioso e suas funções de entorpecimento, verificase uma possível sustentação metafórica, necessária para qualquer formação de sintoma. Por outro lado, ao retomar as referências de Lacan quanto ao discurso do capitalista como o discurso do mestre contemporâneo, a questão é de sustentar a possibilidade de a droga fazer obstáculo ao livre funcionamento do gozo do mestre nesse discurso.

Palavras-chave: Toxicomania, sintoma, discursos, histeria, desejo 


\section{Preâmbulo}

Problemáticas como a toxicomania e o narcotráfico vêm interessando diversas áreas do saber. Do discurso jurídico ao psicanalítico, passando pela sociologia, antropologia, medicina e psicologia, buscam-se abordagens que apontem caminhos para lidar com suas questões. Já em 1993, Joel Birman chamava a atenção para o fato de que a exclusividade e o domínio que a farmacologia e a medicina detinham sobre a questão das drogas havia sido superada por um interesse compartilhado entre diversas disciplinas. Uma vez que as primeiras se mostraram limitadas, outras áreas do saber foram evocadas a pensar o problema, devido à "urgência social e política que a questão das drogas colocou no espaço social" (Birman, 1993, p. 58).

$\mathrm{Na}$ realidade, o interesse em torno do tema denuncia sua importância social. Entretanto, é preciso cuidado com as várias facetas da interdisciplinaridade que o ronda pois, muitas vezes, a preocupação social termina por levar a estudos mais epidemiológicos do que propriamente clínicos, de maneira que os casos são abordados a partir de classificações e diagnósticos generalizadores, o sujeito, ele mesmo, correndo o risco de ser deixado de lado. Para a psicanálise, ao contrário, é preciso, acima de tudo, trabalhar com a fala de cada sujeito, em vez de tender a generalizações. E é justamente a partir da escuta clínica que algo pode se revelar sobre o tema. Nesse contexto, por inúmeras que sejam as formas de consumo de drogas, o que as diferencia 


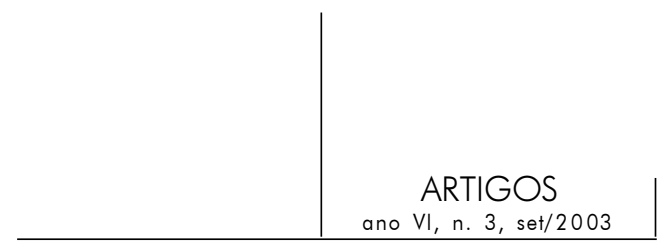

é a importância que a substância tem para cada sujeito, sua relevância na vida de cada um. Por exemplo, não é raro encontrarmos sujeitos que, apesar de fazerem uso de drogas regularmente e há vários anos, não se consideram dependentes, pois a droga não ocupa um lugar importante em suas vidas e por isso não lhes causa nenhum tipo de problema. Por outro lado, há quem consuma drogas com a mesma freqüência e ao longo do mesmo período de tempo que os primeiros, mas se considera um toxicômano porque a droga se tornou a razão de sua vida, além de tê-la transformado radicalmente.

Durante muitos anos, o fato de a psicanálise visar a clínica do um a um levou a críticas do tipo: a psicanálise não se importa com o social, a psicanálise é um discurso individualista, não leva em conta a sociedade. Malgrado o amplo direito de resposta já exercido nos últimos anos a esse tipo de crítica, há sempre que se perguntar pelos instrumentos que existem na teoria psicanalítica para dar conta da inserção do sujeito no social. O texto que segue, tirará consequiências do próprio fato de tal inserção, a partir do conceito psicanalítico de sintoma.

Para Lacan, o sintoma é, antes de mais nada, um conceito marxista. Toda vez que Lacan introduz o tema do sintoma, qualquer que seja o contexto, ele sempre lembra que o conceito de sintoma vem de Marx - e não há dúvida de que as contribuições de Marx levem em conta a sociedade. É nesse âmbito também que se constrói a tese de Jésus Santiago, a ser retomada mais adiante, segundo a qual a toxicomania é necessariamente efeito de discurso - não há toxicomania natural - e, atualmente, particularmente efeito do discurso da ciência, na medida em que este discurso exclui os efeitos de gozo das próprias drogas cuja toxicidade calcula (Santiago, 2000).

Além disso, é o conceito de sintoma que melhor convém ao trabalho psicanalítico que se sustenta no caso a caso. Os sintomas falam, podendo revelar uma verdade singular e fundamental para cada sujeito. Sintoma e verdade se articulam: o sintoma veicula uma verdade, colocando em evidência um saber sobre o recalcado. Embora desde Freud o "invólucro formal do sintoma" (cf. Lacan, 1966, p. 66) tenha variado, e as histéricas de hoje não apresentarem muitas vezes os mesmos sintomas que as do fim do século XIX, a estrutura permanece a mesma, observa Elisabeth Roudinesco (2000, p. 23). Um exemplo da mudança na apresentação atual do sintoma tange a depressão: referência a um invólucro formal do sintoma em nosso tempo, e isso desde a publicação, em 1984, do texto de Diana Rabinovich.

Para tentarmos provar nossa hipótese de que é possível verificar a toxicomania como equivalente ao sintoma no discurso da histérica - o que não quer dizer que ela só assim se verificaria -, este texto se dividirá em três partes: fenômeno e estrutura, sintoma e clínica. 


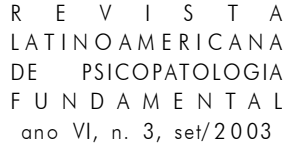

\section{Fenômeno e estrutura}

Muitas são as contribuições da psicanálise no campo das toxicomanias. Tal diversidade se produz a partir da variedade de abordagens teóricas e clínicas possíveis no trato da questão, devido à multiplicidade de leituras da teoria psicanalítica. A complexidade do tema ganha ainda maior força em razão da já aludida interdisciplinaridade devido à "urgência social e política que a questão das drogas colocou no espaço social" (cf. acima).

Partindo de uma revisão bibliográfica - que restringimos em função do espaço - de alguns autores brasileiros e suas referências textuais, são basicamente duas as vertentes do saber psicanalítico sobre o assunto nos últimos quinze anos: uma que considera a toxicomania um fenômeno, passível de ocorrência em qualquer uma das três estruturas clínicas propostas pela psicanálise, ou seja, neurose, psicose e perversão, e outra que a define exclusivamente como perversão, atribuindo-lhe um lugar como tipo clínico da estrutura perversa.

Esta segunda vertente encontra-se argumentada desde 1986 por Birman: a toxicomania se inscreve na estrutura perversa (p. 200). Remetendo-se ao filme de Fassbinder, $O$ desespero de Verônica Voss, Birman associa a relação dos toxicômanos com a droga à desesperada e desenfreada busca dos sujeitos por algo que os livre do sofrimento, por meio de uma fórmula mágica que lhes conceda não saber suas condições fundamentais, o uso da droga denunciando uma inabilidade em lidar com o mal-estar na cultura e sua conseqüente angústia, desmentindo-a. A preocupação do autor em manter o referencial estrutural freudiano é notória. Assim, ele tece críticas: por um lado, aos que tenderam a apagar a discriminação estrutural, em particular a certos textos de influência kleiniana que teriam reduzido muitos fenômenos da clínica a defesas diante de experiências psicóticas (Ibid., p. 207); por outro lado, a textos de influência norteamericana que se afastaram da perspectiva psicanalítica modelando a clínica de acordo com pressupostos roubados à psiquiatria dos manuais. Além disso, tece críticas a autores que, diante de tantas incertezas nosográficas, procuraram apagálas com a proposta de uma quarta estrutura, na qual seria possível inserir tudo o que não cabe nas estruturas já estabelecidas.

Birman identifica Radó como o primeiro autor da tradição analítica a lidar com a "questão espinhosa" das toxicomanias, fornecendo uma elaboração sistemática para o tema, não sem lançar mão de um organicismo quase bioquímico para conceituar a libido. A partir do conceito de orgasmo alimentar, Radó articula as toxicomanias com o registro da oralidade. Assim, haveria uma impossibilidade na experiência do desmame e, em conseqüência, uma busca pela restauração "de 


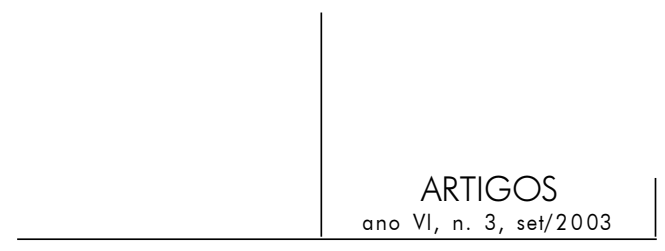

um estado primário de satisfação absoluta, do qual seria impossível se privar" (Ibid., p. 210). Segundo Birman, Radó desenvolvia pesquisas sobre as farmacotimias e, a partir de trabalhos de Freud e Abraham, sobre a melancolia; de Freud e Rank sobre o narcisismo, e de Abraham sobre as fases da fixação da libido, o que promoveu a articulação entre as variações de humor nas toxicomanias, com oscilações entre mania e depressão. A mania corresponderia à busca desenfreada do orgasmo alimentar originário e a depressão indicaria a impossibilidade deste, "que o toxicômano tenta restabelecer com o uso compulsivo da droga" (Ibid., p. 211). Posteriormente, outros autores orientaramse por esta vertente. "Assim, a constatação repetida de que os toxicômanos existem no universo oral, (...) atravessa a literatura psicanalítica” (Ibid.), produzindo interpretações do recurso à droga como uma tentativa de suprir a falta de uma relação materna satisfatória.

Tomar as variações do humor e as oscilações entre mania e depressão como parâmetros para determinar a questão dos toxicômanos é, definitivamente, esvaziar qualquer referência possível a uma clínica estrutural, ou seja, uma clínica que se baseie nas referências freudianas da castração e do Édipo. Tudo isso acaba por desvitalizar a própria clínica psicanalítica, a que faz valer o desejo.

Ao contrário, quando se sustenta o trabalho na referência psicanalítica, todo fato clínico, como também observa Birman, deverá ser referido justamente à articulação estrutural dada pela função paterna, e é por isso que julga "reencontrar a problemática da paternidade nas toxicomanias e estabelecer os contornos da estrutura perversa" (Ibid., p. 212). É em função do que a estrutura perversa comporta de negação da castração que Birman a associa à toxicomania, prática que implica, se não o velamento, o desmentido ou recusa do mal-estar na cultura. Assim, os pólos maníaco e depressivo da experiência psíquica toxicômana ocorrem em função da ingestão da droga, ou seja, secundariamente à drogadição, com efeitos que levam o sujeito a velar a castração - a mania - e sua contrapartida, o cessar desses efeitos, que revela o fracasso de sua tentativa - a depressão; e a drogadição seria determinada pelo próprio fato da estrutura perversa - aquela que nega a castração, por definição. Provavelmente em sua tese há fundamentos a serem revistos, pois considera que, uma vez não estando inscrito simbolicamente na perversão-toxicômana, o pai seria um pai ideal, que por isso pode ser recusado e aniquilado, não impedindo o sujeito de se colocar no lugar do falo. Tal argumentação levanta a questão sobre que tipo de relação o autor faz entre a não inscrição simbólica do pai e a perversão. Não nos cabe, no entanto, desenvolver esse ponto no presente texto.

Birman classifica cada uma das relações com a droga, afirmando a existência de dois grupos de individualidade distintos - os usuários de drogas e os toxicômanos. O critério para esta distinção é o funcionamento psíquico, já 


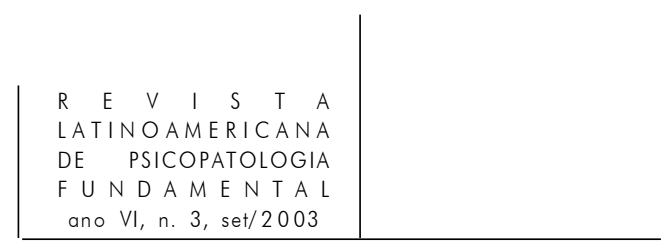

que os dois grupos possuem "unidades clínicas diferenciadas". Para o autor, toxicômanos e usuários de drogas "se diferenciam pela dimensão compulsiva que marca a ingestão da droga" (Birman, 1993, p. 61). Os usuários de droga podem ser consumidores regulares ou irregulares de drogas, podem recorrer a elas para a obtenção de prazer ou em momentos de angústia. Entretanto, a droga não se transforma na razão de suas vidas. Nestes casos não se desenvolve uma dependência física, mas sim uma certa dependência psíquica. Ao contrário, os toxicômanos propriamente ditos, apresentariam a dimensão compulsiva, "são compelidos à sua ingestão por forças físicas e psíquicas poderosas" (Ibid.). Aqui, as drogas possuem valor soberano sobre a existência destes sujeitos, regulam suas vidas. As dependências física e psíquica estão presentes de forma esmagadora, a ponto de a dependência física exigir dos sujeitos doses cada vez mais fortes, além da substituição de drogas cada vez mais potentes. Os toxicômanos se inseririam na estrutura perversa, em que a droga funciona como objeto fetiche, objeto parcial, que ao ser incorporado dá ao sujeito a ilusão do restabelecimento de seu lugar de phallus materno (sic), enquanto os usuários de droga poderiam se inscrever em qualquer estrutura. Não fica claro, no entanto, por que isso ocorreria obrigatoriamente.

É importante perguntar se, para a psicanálise, o fato de existirem sujeitos diferenciados que fazem uso de drogas autoriza a criação de estruturas definidas de acordo com estas distinções fenomenológicas. Ou seja, de que forma elas garantem a definição de uma estrutura clínica específica? Retornemos a Freud (1930) que considera o recurso às drogas uma medida paliativa, uma maneira de lidar com o mal-estar. A questão é que, em qualquer caso, os sujeitos parecem recorrer às drogas por não quererem ou não poderem lidar com o mal-estar, inerente ao ser falante, o que Birman certamente leva em conta.

De nossa clínica é importante observar que jamais o fenômeno pode determinar a estrutura; na realidade, cada sujeito estabelecerá relações com as drogas cujas intensidades e formas serão sempre meios singulares da inabilidade dos sujeitos em lidar com o desprazer, o mal-estar, ou seja, a castração. É a partir da relação com a castração que o exame estrutural irá identificar a maneira pela qual cada sujeito se inscreve nas estruturas psíquicas, identificando com isso o processo de construção das subjetividades, estejam elas ligadas ou não ao consumo de drogas. Neurose, psicose e perversão são as estruturas que surgem como respostas ao enigma da castração. No referencial psicanalítico, estas são as três únicas formas de estruturação dos sujeitos e irão definir sua relação com a realidade, já perfeitamente definida por Freud, em 1924, como aquela a que se tem acesso pelo prazer (Santiago, 2000, p. 26).

Discutindo a hipótese da estrutura perversa para os toxicômanos, o texto que Jésus Santiago publicou em 1993, “Toxicomania e perversão”, estrutura sua 


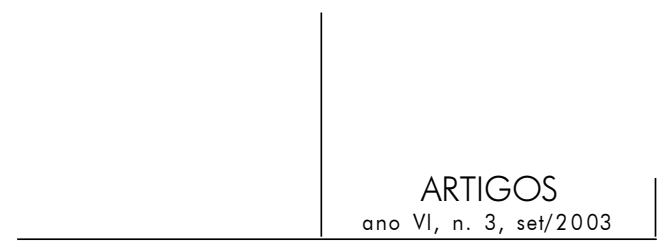

crítica em torno de uma leitura particular do teórico americano Edward Glover. Glover é mais um autor que sustenta a hipótese da estrutura perversa na toxicomania, como resposta à angústia primordial. É claro o referencial kleiniano a que Glover recorre para definir a toxicomania: à medida que a define como proteção do sentido de realidade, estabelece o funcionamento das perversões como modalidade de defesa face à experiência da psicose - posição bastante similar àquela observada por Birman no texto de Radó. Segundo a leitura feita por Santiago das referências de Glover, há um remanejamento das estruturas clínicas, situando-se a toxicomania como uma fase intermediária entre "o que se define, cronologicamente, como primitivismo das psicoses e a organização ulterior das neuroses" (Glover, apud Santiago, 1993, p. 75). A perversão como conseqüência de uma dificuldade na estruturação psíquica surgida antes de uma possível estruturação neurótica, no referencial teórico que estabelece fases para o desenvolvimento psíquico, implica a droga como instrumento de defesa contra uma psicotização, proteção "como um meio de conter a descompensação própria do que não se pode exprimir numa realidade corrente" (Ibid.). Assim, a saída toxicômana consistiria na renúncia às libidinizações primitivas por meio da droga ou do fetiche. Saída fetichista, que conservaria as taxas de realidade em todos os domínios, exceto naquilo que diz respeito ao fetiche, para o perverso, ou à droga, para o toxicômano (sic).

Mas, como bem observa Santiago, a hipótese freudiana sobre a perversão não autoriza uma referência ao fetichismo enquanto mecanismo que permitiria preservar o sentido de realidade. A proteção diz respeito a uma perda da realidade específica, a perda da realidade da perda do falo materno que, na perversão, é desmentida (cf. Freud, 1927). Trata-se da realidade da castração, e não da realidade enquanto puro investimento de objetos. O paralelo entre droga e fetiche, proposto por Glover, estabelece a noção de que estes, enquanto objetos parciais, tornam-se o ponto de regulagem das relações objetais. Santiago argumenta que este paralelo, no âmbito das discussões atuais sobre as toxicomanias, não é completamente sem valor. O fetiche advém de uma substituição, instalada sob o fundo da angústia de castração. Como já vimos, Freud (1930) refere-se à droga como uma construção substitutiva. Entretanto, esta substituição "apresenta-se com muito mais clareza no caso do fetiche, pois designa então, precisamente, a ausência do falo materno" (Santiago, 1993, p. 77). Já no caso da droga, devese admitir que há uma indefinição do elemento que será substituído, que só se determina em função da estrutura do sujeito em questão.

Desta forma, Santiago define a substituição promovida pela droga segundo uma outra perspectiva. Se a droga é um produto de substituição, é porque está articulada com "o revestimento de angústia que se tece em torno do gozo fálico" (Ibid., p. 77). O recurso à droga seria, então, a forma que o toxicômano 


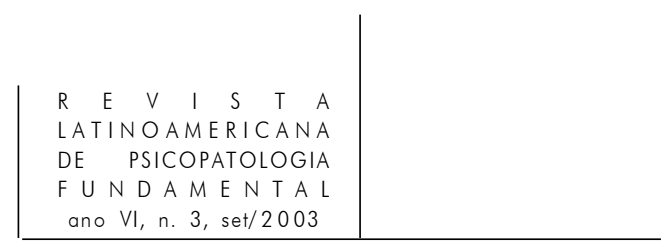

encontra para lidar com a angústia derivada do embate dos sujeitos "com essa parte do gozo que deveria ser absorvida pelo significante fálico" (Ibid., p. 77).

Até aqui parece clara a argumentação de Santiago em defesa de uma concepção da toxicomania enquanto fenômeno. Entretanto, no decorrer da defesa de seu posicionamento, Santiago introduz uma outra via, a da articulação entre toxicomania e gozo, bem mais complexa de acompanhar por basear-se nos conceitos de gozo em Jacques Lacan, e diante dos quais muitos leitores recuam. É interessante observar com Santiago, que esta interpretação pode novamente inserir a toxicomania no campo da perversão, agora com novos parâmetros: identificado ao objeto droga, o sujeito sustenta o gozo do Outro. $\mathrm{O}$ autor ressalta que tal aproximação da toxicomania à perversão é também insuficiente e que "seria necessário demonstrar-se em que medida a identificação à posição de objeto, própria à prática toxicomaníaca da droga, é depositária do uso perverso do fantasma" (Ibid., p. 79). A partir de uma articulação com o importantíssimo texto de Jacques Lacan "Kant com Sade" (1963), identifica e questiona a droga no lugar de objeto $a$ a comandar o sujeito e a promover sua divisão, visando a completude do Outro. Afirma que, se na perversão o objeto da pulsão se presta à vontade de gozo, não é o que ocorre na toxicomania, pois a prática toxicomaníaca não remete à recuperação de gozo e nem a uma forma de lidar com as vias complicadas do fantasma. Pelo contrário, produziria um atalho que permitiria evitar o fantasma e por esta razão, não se pode definir a toxicomania como perversão. Isso não significa que não existam toxicômanos perversos, "mas que, simplesmente, não o são em seu trato desregrado com a droga" (Ibid., p. 80). Tal afirmação leva a entender que, mesmo na perversão, a relação do sujeito com a droga não se estabelece de forma perversa. Fica a cargo do leitor a solução de mais este instigante enigma e podemos concluir em Santiago uma aposta que tende à identificação da toxicomania como fenômeno, capaz de se presentificar em qualquer estrutura clínica.

Em acordo com esta posição de Santiago, no que se refere à toxicomania enquanto um fenômeno, está também Bittencourt. Em seu texto "Algumas considerações sobre a neurose e psicose nas toxicomanias" publicado na mesma edição que o de Santiago, em 1993, refere-se ao lugar do objeto-droga no âmbito das estruturas clínicas incluídas no título de seu trabalho. Lígia Bittencourt não concebe a abordagem do tema fora da prática clínica, mas a partir dela, na transferência, e é por isso que começa já chamando a atenção para a importância das entrevistas preliminares no deciframento da estrutura clínica dos sujeitos usuários de drogas, o que será fundamental para o processo de análise. O importante é ater-se ao discurso do sujeito, poder escutá-lo, e não estabelecer a regra de que todo toxicômano é perverso. Ser toxicômano, por si só, não diz nada do sujeito. 


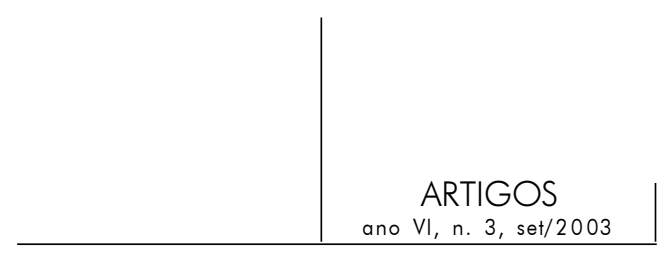

Para nosso trabalho aqui, e nossa hipótese, é fundamental a observação da autora, de que, conforme sua experiência clínica, a adição às drogas configura uma situação de desaparição do sujeito do desejo, quando este se vê diante do mal-estar. Quando algo se constitui como intolerável e não pode ser simbolizado, o recurso às drogas surge como saída. Se, por um lado, nas toxicomanias o sujeito fica em suspenso por não poder ou querer lidar com o mal-estar, isto não significa que esta saída seja escolhida por todos os toxicômanos pelos mesmos motivos e nas mesmas condições. Pode-se concluir, então, que o que norteia o uso de drogas está relacionado com a estrutura clínica que é dada na singularidade de cada sujeito. A autora faz um esforço para justificar esse ponto de vista, absolutamente convincente, demonstrando como a droga pode entrar na economia libidinal em qualquer estrutura. Certamente qualquer exame de caso clínico se beneficia das articulações da autora. Até aqui o texto de Bittencourt defende e sintetiza, de forma clara, a toxicomania como fenômeno que não está associado, particularmente, a nenhuma das três estruturas clínicas e que, por isso, não pode ser fundado sobre um mito comum.

No entanto, é bastante taxativa: a função da toxicomania vem na contramão do sintoma. Na realidade, a função da toxicomania seria evitar os sintomas dos sujeitos, agindo como uma máscara para estes sintomas, obscurecendo, por exemplo, a definição do diagnóstico estrutural. Fato, aliás, observado por outros autores também. Segundo ela, o dispositivo da toxicomania opera "como um modo de resposta permanente que se substitui à exigência de uma elaboração psíquica e apazigua o sujeito diante de um intolerável" (Bittencourt, 1993, p. 83). Assim, a toxicomania parece ser uma das maneiras encontradas pelo sujeito para responder aos "impasses que renovam e relançam o laço do sujeito à castração" (Ibid.) sem, entretanto, recorrer ao trabalho de simbolização. Diante do mal-estar, o sujeito recorreria à droga como uma resposta não simbolizada.

Para além da clareza com que o texto vinha sendo desenvolvido até aqui, surgem algumas questões: O que significa evitar sintomas? A toxicomania seria uma tentativa de rechaço do sujeito à sua própria estrutura psíquica na medida em que sua função é evitar os sintomas? Por isso seria uma tentativa de não lidar com a castração, de não lhe dar uma resposta, em oposição ao que ocorre no processo de estruturação psíquica? A quais exigências a autora se refere? A elaboração psíquica (sonhos e sintomas) que deveria vir no lugar da ação de se drogar são exigências de quem? Que estatuto então para o uso de drogas? O do ato? Inúmeras questões que, certamente, poderão levar a tantas outras observações. 


\section{O sintoma}

É nesse âmbito que poderíamos também retomar a observação de Freud, segundo a qual a toxicomania é a própria narcose da neurose (1927, p. 182), da qual deriva ainda a de Fernando Grossi quando nos diz: "Ao invés de haver o caminho da formação do sintoma que faria um laço, vamos chamar, simbólico, através, por exemplo, de uma fobia - como no caso Hans -, o sujeito faz o curtocircuito da droga" (2000, p. 38). Também aqui observa-se a vertente da toxicomania na contramão do sintoma. Nesse âmbito, seria possível supor a clínica das toxicomanias dizendo respeito, exclusivamente, à questão do gozo sem qualquer relação com as formações do inconsciente (cf. Viganò, 1997).

Mas se olharmos mais de perto, no mínimo também seria possível dizer exatamente o contrário. Por exemplo: A frase na qual Freud observa que a toxicomania é a própria narcose da neurose, diz o seguinte na sua textualidade: "Talvez aquele que não sofre de neurose tampouco necessite de uma intoxicação que a narcotise" (1927, p. 182, grifo meu). Ou seja, no fundo, a intoxicação necessariamente imprescinde da neurose, mesmo se a escamoteia, porque o sujeito sofre com a neurose na medida em que esta não é a forma mais eficaz de se lidar com a castração. É interessante, por exemplo, ler a descrição que Freud (1916-1917) faz do sintoma em sua conferência a este respeito; ali fica clara a relação do sintoma com o embaraço da satisfação. Freud observa que, entre as coisas que promovem nosso estranhamento diante dos sintomas, uma é particularmente interessante: eles não permitem que os identifiquemos com nada que diga respeito aos usuais caminhos de obtenção de satisfação de um sujeito que possa se exercer levando em conta a castração, ao contrário, normalmente os sintomas implicam um

... retorno a um tipo de auto-erotismo difuso, do tipo que proporcionava a pulsão sexual nas primeiras satisfações. Em lugar da modificação no mundo externo, essas satisfações são substituídas por uma modificação no próprio corpo do sujeito: estabelecem um ato interno em lugar de um externo, uma adaptação em lugar de uma ação - uma vez mais, algo que corresponde, filogeneticamente, a uma regressão altamente significativa. Isto só compreenderemos em conexão com algo novo que ainda teremos que aprender das pesquisas analíticas acerca dos sintomas. (Freud, 1916-1917, p. 357[428])

Esse retorno a um tipo de auto-erotismo difuso, o próprio sintoma, tem por fim evitar a angústia da castração, antes de mais nada, como reformula Freud em todo seu texto de 1926. Ora, não é justamente disso que em muitos casos se trata na narcose? Narcotizar a neurose via auto-erotismo difuso, não submetido aos usuais caminhos de obtenção de satisfação, como Freud já dizia em 1916- 


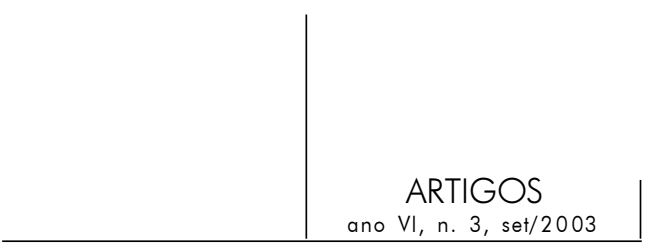

1917, e que Lacan retomou sob o signo da ruptura do gozo toxicomaníaco com o gozo fálico?

É o aprofundamento desta última pergunta que, finalmente, nos abre o caminho para encontrar uma possível equivalência entre determinadas manifestações do fenômeno toxicomaníaco e o sintoma. Equivalência ${ }^{1}$ aqui no sentido de que uma possa substituir a outra, no lugar disso, aquilo. Como escreveu Santiago, mais recentemente: “... o recurso da droga instala-se como uma espécie de construção substitutiva e auxiliar do sintoma, considerado na sua acepção mais clássica de retorno do recalcado" (2000, p. 154). Há uma interessante passagem em "Inibição, sintoma e angústia" sobre uma possível equivalência da moção pulsional e da compulsão. Neste texto, Freud observa que, malgrado esse equivalente ser enfraquecido, deslocado e inibido e não ser mais identificável à satisfação, "sua realização apresenta, ao contrário, a marca da compulsão. No entanto, nesse rebaixamento da realização de satisfação para um sintoma, o recalque mostra seu poder em ainda um outro ponto..." (Freud, 1926, p. 240[90]). Ou seja, para Freud, a compulsão aqui produzida é um sintoma, mesmo se já não implica o investimento de objeto; mesmo sendo auto-erótico difuso justamente porque não leva a uma ação que poderia trazer a satisfação a partir de um objeto, e mesmo sendo um simples substituto - equivalente - da moção pulsional. Com efeito, oito capítulos depois, quando então Freud já está tratando da questão da pulsão de morte na articulação com a neurose, observa que o próprio fator de fixação do recalque, ou seja, aquela adaptação auto-erótica, efeito de uma regressão filogeneticamente altamente significativa, é a compulsão à repetição. Esta, "normalmente só é eliminada pela função do eu de mobilidade livre" (Ibid., p. 292[144]) - quer dizer, de um eu que adveio do isso, como Freud o postula para a direção do tratamento analítico, um eu sadio. Ora, um eu sadio, como produto do "Wo es war soll ich werden" ("onde isso era devo advir"), certamente não é o do neurótico, aquele que recua frente à castração e às determinações inconscientes.

Diante disso, nada impede à toxicomania andar junto com a neurose, a partir de Freud! Além disso, é aceitável supor uma relação possível da droga com o pai, na medida que Freud associa a toxicomania com a religião. Como bem mostra Freud em 1927, a religião pode equivaler não só à toxicomania como à estimulação, à droga e a outros meios de obtenção de prazer, o que fica claro

1. Optamos pela tradução proposta por Lacan, do termo freudiano Ersatz, ou seja, equivalência, na medida em que julgamos que essa tradução explicita, em si, seu próprio mecanismo: uma coisa se substitui a outra por via da equivalência, o que necessariamente imprescinde do significante. 


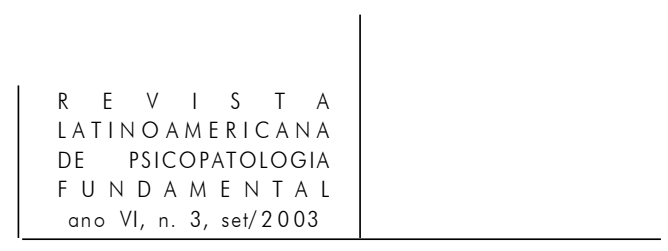

com o que aconteceu nos Estados Unidos na época da lei seca quando se substituiu tais meios, pelo temor a Deus (p. 182). É esta abordagem freudiana que também fundamenta as observações de Grossi quanto à relação da droga com o ideal, um equivalente à noção de pai como se pode ler em "Luto e melancolia" (Freud, 1917).

Ora, se é possível implicar a droga em equivalências, então é possível pensála no âmbito do sintoma.

Para introduzir esse âmbito, servir-nos-emos de uma referência de Paskvan: O toxicômano pode ser "um objetor ao gozo universalizado da civilização" (1994, p. 69). Observação que se associa à de Melman, segundo o qual o toxicômano pode usar a droga para se subtrair ao gozo do Outro. "Ele não goza da droga, mas do fato de desligar-se do gozo do Outro" (1992, p. 135).

Se nos associarmos a Santiago (2000, p. 60) e tomarmos emprestado de Lacan o conceito de sintoma tal como ele o desenvolve em "A terceira", "o sentido do sintoma é o real, o real enquanto pedra que se põe no caminho ${ }^{2}$ para impedir que as coisas funcionem de tal forma que sejam satisfatórias para os mestres..." (Lacan, 1974), então o toxicômano que usa a droga para se subtrair ao gozo do Outro pode fazer dela sintoma, gozando tal o escravo de que Lacan fala na seqüência de seu texto.

Três acepções do conceito de sintoma: como compromisso, no sentido freudiano do termo, sustentado na fantasia; como cruz (ou, para retomar a poesia de Drummond, pedra no caminho) que impede com que as coisas funcionem de forma a satisfazerem o mestre; como quarto elo, no nó que nem sempre é borromeano.

Bem, se é possível encontrar equivalências para o fenômeno toxicomaníaco na fala do sujeito, ou seja, verificar equivalências para além da substituição da moção pulsional existente em todo sintoma, o fenômeno responde à primeira acepção.

\section{A saída pelo discurso do analista}

Quanto à segunda acepção, é necessário identificar o mestre ao qual a "cruz" faria resistência. Nossa hipótese é a de que se trata do próprio S1 no discurso do capitalista, a sustentar promessas de felicidade a partir do consumo

2. Tradução em homenagem às comemorações do centenário de nosso poeta Carlos Drummond de Andrade. 


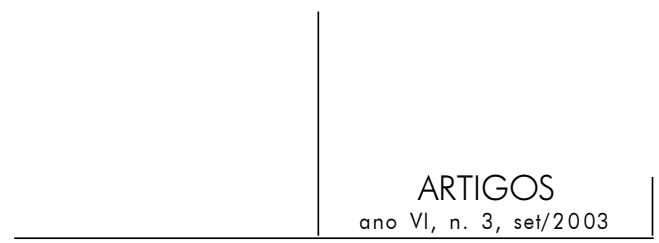

tanto de drogas lícitas quanto das ilícitas. Para justificá-la é necessário retomar tal discurso conforme as indicações de Lacan. O discurso do capitalista é uma corruptela do discurso do mestre (Alberti, 2000). Uma primeira diferença, no entanto, é que no discurso do capitalista o sujeito se crê agente, mas isso é só um semblante, na verdade, tal como no discurso original, o do mestre, agentes são os $\mathrm{S} 1$, as marcas dos gadgets às quais o sujeito se submete. ${ }^{3}$ Da mesma maneira que no discurso do mestre, é o S1 que se dirige a S2, mas o S1 está no lugar da verdade e o S2 no lugar do gozo. Os objetos da mais valia, produtos dessa orientação, no entanto, não caem do discurso, não se perdem, são reaproveitados e o sujeito que no discurso do mestre é impedido de aceder ao gozo, pode dele usufruir; o gozo é possível de forma que a castração fica foracluída e o sujeito fixado no lugar que o S1 determina. "É como se pudéssemos dizer: o Discurso do Capitalista não exige a renúncia pulsional; ao contrário, ele instiga a pulsão, impondo ao sujeito determinadas relações com a demanda, sem se dar conta de que, ao fazê-lo, sustenta sobretudo, e em primeira mão, a pulsão de morte" (Ibid., p. 47).

Se o mestre do discurso do capitalista promove o "nada se perde, tudo se transforma" ${ }^{4}$ - na medida em que o próprio desse discurso é desmentir a castração, o sujeito histérico pode muito bem se utilizar da droga para recusarse ao trabalho, ao estudo, à produção, obstacularizando, dessa forma, a satisfação do mestre atual. No entanto, é fundamental que isso possa ser assim validado pelo discurso do analista. Como já dizia Lacan (1974a) em Televisão, o único discurso a poder fazer frente ao discurso do capitalista é o discurso do analista, o que se dirige ao sujeito no lugar do outro. Então, no discurso do analista, já pelo fato de o analista receber um sujeito e não um toxicômano, ou seja, já pelo fato de o analista atribuir a seu paciente o estatuto de sujeito independente das identificações que o distingam no Outro social, já por esse fato, ele poderá promover um giro de discurso e permitir ao sujeito agenciar um discurso em que o uso da droga revela a verdade singular e recalcada que o mestre tanto desconhece quanto desvaloriza. Com o discurso do analista é possível promover a saída do discurso do capitalista, a instalação de um outro

3. Aqui é necessário tomar nota do fato de que Lacan já não denomina os lugares da mesma maneira que no Seminário XVII. O que ali era o agente, aqui é o semblante; o que ali era outro, aqui é gozo; o que ali era produção, aqui é mais-de-gozar, mantendo-se somente a referência à verdade.

4. Santiago, 2000, observa a relação intrínseca do gozo pulsional com o valor atribuído pelo discurso capitalista ao que não serve para nada e que pretende reaproveitar até mesmo o gozo pulsional (p. 59). 


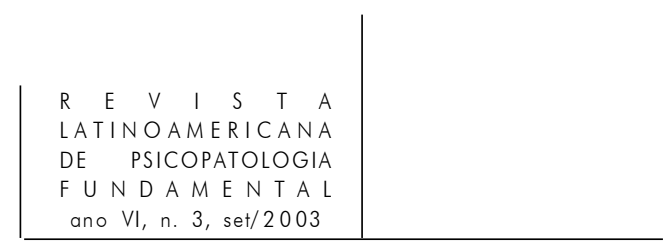

discurso em que o sujeito não é mais engano de agente (como ele o é no discurso do capitalista), mas agente propriamente dito, como sempre o foi no discurso da histérica.

Cem anos após os estudos sobre a histeria, a histeria é cada vez mais tratada como uma depressão e submetida ao método químico de tratamento sem que se leve em conta qualquer causalidade psíquica oriunda do inconsciente. No entanto, o inconsciente ressurge por meio do corpo da histérica, opondo uma forte resistência às práticas que visam a repeli-lo. A concepção freudiana de um sujeito do inconsciente, atormentado pelo sexo, pela morte e pela interdição, foi substituída pela concepção psicológica de um indivíduo depressivo, que rechaça o inconsciente, evitando o conflito. Daí decorrem novas questões que podem interessar o aprofundamento do estudo das toxicomanias, em particular em sua articulação com a neurose. Se uma das versões atuais da histeria é o "deprimido" que nesse início de século recorre às drogas, buscando o ideal de uma felicidade prometida - cuja inacessibilidade a droga no discurso capitalista nega -, seria possível pensar a toxicomania como um outro invólucro formal do sintoma na neurose? Em 1998, Grossi e Nogueira já levantavam a questão sobre um invólucro formal, além disso, estimulado pela aliança entre medicina e psicofarmacologia que pode causar uma relação bastante complexa até mesmo para o discurso histérico: o mestre doutor no lugar do outro é questionado pelo sujeito histérico que se utiliza, para isso, das próprias drogas que o mestre doutor lhe receitara e que já não fazem o efeito esperado por aquele ou propagandeado pelo laboratório que as produziu. Esta é a hipótese que levantamos e que também encontra eco nas observações das mais recentes pesquisas, segundo as quais há risco de benzodiazepínicos provocarem graves sintomas e fenômenos de dependência, de forma que a própria aliança da medicina com esta ciência dos psicofármacos, que não deixa de se fazer sob fundo do interesse dos laboratórios de medicamentos, quer dizer, sob base do discurso capitalista, cria novas formas de sintoma. Tendo em vista a importante influência do discurso da ciência em nossas vidas atualmente, é preciso observar a relação do sujeito com a droga lícita ou ilícita - como efeito de discurso: “... produto das mudanças operadas pela emergência do discurso da ciência no mundo" (Santiago, 2000, p. 29). É nesse sentido que esse autor chega a elevar a toxicomania a paradigma das novas formas de sintoma, pois é ela a que melhor exemplifica o modo de gozar autístico por meio do qual se tenta prescindir do Outro (Ibid., p. 14), na vertente do eu não penso - aquela através da qual o eu se quer livre das determinações do Outro (cf. Alberti, 1998 e Santiago, 2000, p. 191).

Com efeito, o próprio discurso da ciência é utilizado aqui para sustentar a publicidade dos laboratórios, o que se vê particularmente nas campanhas publicitárias norte-americanas. Recentemente, o Programa Sixteen Minutes da 


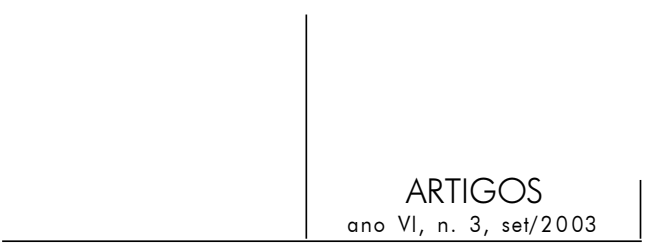

televisão americana ${ }^{5}$ denunciou campanhas publicitárias que chegaram às raias de enviarem gratuitamente à casa de alguns clientes de farmácias, medicamentos antidepressivos de longo efeito, sugerindo grandes ganhos no dia-a-dia da vida moderna, justificando-se científica e tecnicamente - mais uma vez excluindo os efeitos de gozo no sujeito! Estes seriam, ainda segundo a tese de Santiago (2000), os efeitos que sustentam a nova forma de sintoma em questão.

O problema é que entendemos que, para verificar nossa hipótese, há que se examiná-la no contexto do discurso do analista, como já dito, o único que reserva ao outro o lugar de sujeito. É a partir disso que o analista pode promover um giro de discurso que permite a associação desta nova forma de sintoma com a histeria. Sabemos o quanto o discurso da histeria se insurge, antes de mais nada, contra o pior mestre, aquele que se assenta na mortificação do sujeito, pelo simples fato de que não há sujeito no mundo mais adepto a fazer valer o desejo do que o sujeito histérico. Assim, será necessário também verificar as versões desse possível invólucro formal do sintoma em suas relações com o que faz objeção à aliança do mestre doutor com o discurso do capitalista, ou seja, retomar as versões do sintoma e suas funções na relação com o desejo, desde que o discurso do analista possa sustentá-lo. Não foi à toa que Lacan insistiu no fato de que é o discurso do analista aquele que mais instrumentos tem para resistir ao discurso do capitalista, por ser, ele mesmo, operador de giros de discursos.

Para além da acepção do sintoma como cruz, ou pedra no caminho, identificamos ainda duas outras acepções do sintoma: o sintoma como efeito do simbólico no real, articulado ao gozo fálico e portanto à fantasia, e o sintoma como quarto nó. Em função da conceituação da primeira acepção, sabemos que necessariamente o sujeito em questão é neurótico e histérico ou histerizado na sua relação com o discurso analítico. Como dito, o sujeito histérico é o mais adepto a fazer valer o desejo; isso porque ele se sustenta na sua própria verdade agalmática.

Se, além de neurótico ele é histérico ou histeriza, então o sintoma como sentido do real se ancora na própria verdade do discurso:
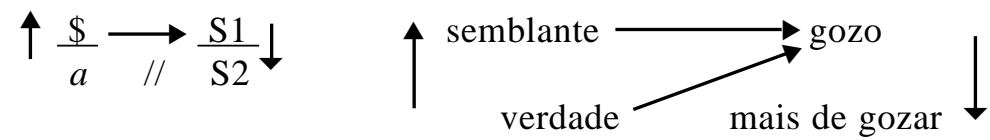

Para analisá-lo, servir-nos-emos de uma outra referência de Lacan, a das conferências conhecidas sob o título "O saber do psicanalista" (Lacan, 1972).

5. Retransmitido no Brasil na noite de 1 de junho de 2003. 


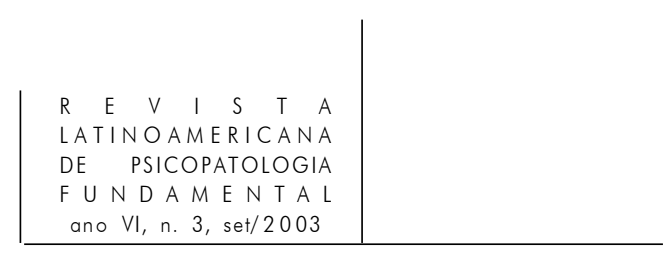

Ali Lacan observa que, em nível da verdade, há dois vetores que divergem quando se estuda a relação sexual, ela mesma como laço social: de um lado, a verdade se dirige ao gozo, o que exprime que o gozo que se encontra no final do ramo direito é, com certeza, um gozo fálico, mas isso ainda não pode querer dizer gozo sexual; de outro lado, a verdade se dirige ao semblante, pois a relação sexual implica a castração e, para que aí se mantenha o ser falante é preciso que ele tenha esse pólo que é correlativo do polo do gozo por obstacularizar a relação sexual, é o pólo que Lacan designa como semblante (lição de 3/2/72). A verdade aqui tem a mesma função que o sentido do sintoma em 1974, na medida em que produz dois vetores (ou seja, dois sentidos) pelos quais o semblante descompleta a própria significação fálica do gozo. Não seria possível aqui pensar o uso da droga nesta função? Ainda aqui não pensamos sozinhas, Santiago já levantara essa hipótese em 2000, em seu capítulo "Vontade de ser infiel ao gozo fálico" (p. 161-83), sem, no entanto, referi-la aos efeitos do bom encontro do discurso da histérica com o do analista.

Com o ato analítico apostando no sujeito desejante, a droga poderia estar no lugar do objeto $a$ no discurso da histérica, de um lado se dirigindo ao gozo fálico e todas as equivalências implicadas na sua determinação significante - os S1 que, na realidade, a nos fiarmos em Freud, estão recalcados -, de outro, à própria passagem do sujeito a semblante, tal como pudemos distinguir para o lugar do sujeito no discurso do capitalista. Eis como a droga poderia se mostrar um compromisso e um quarto elo para suturar o mal estar na cultura atual.

\section{Conclusão}

A bela indiferença na histeria se sustenta até o momento em que o sintoma já não dá conta do mal-estar na cultura, em outros termos, do escamoteio da angústia de castração próprio à neurose. Quando a angústia reaparece, malgrado toda drogadição, o sujeito procura um tratamento. Este, no entanto, é de importante fragilidade: assim que a angústia diminui, o retorno ao antigo recurso é normalmente privilegiado. Afinal, o compromisso funcionava... A toxicomania na neurose é certamente um dos campos em que mais se deve lembrar a advertência de Freud aos analistas: não se deve buscar a resolução do sintoma e não se deve apaziguar a angústia. Uma clínica há que ser aqui construída, mas ela imprescinde do discurso do analista: identificar um sujeito e não um toxicômano, colocar esse sujeito a trabalho com todo sofrimento que ele fizera equivaler à droga, o que exige a presença do analista e de seu ato a apostar no desejo, irrestritamente, intransigentemente até mesmo para o analista. Assim, 


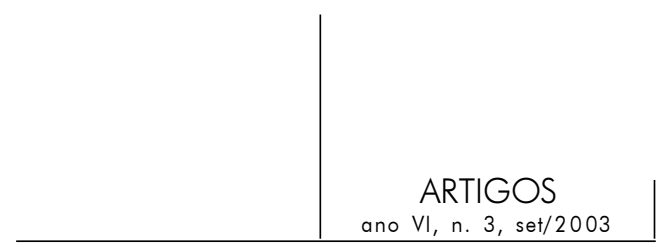

talvez, os inúmeros relatos de casos que já se conhece, e que na grande maioria das vezes terminam nas mãos da medicalização por resistências dos analistas, nos permitam melhor pôr à prova o próprio discurso do analista e o desejo decidido de fazer valer o sujeito por nós herdado de Freud. Uma coisa é certa: não há como fazê-lo para a neurose se não for possível identificar a função sintomal.

\section{Referências}

Alberti, Sonia. Psicanálise: a última flor da medicina. In: Alberti, Sonia e Elia, Luciano (orgs.). Clínica e pesquisa em psicanálise. Rio de Janeiro: Marca d’Água, 2000, p. 37-56.

O quadrilátero no ato psicanalítico. Opção lacaniana. Revista Brasileira Internacional de Psicanálise, n. 21, p. 96-9, 1998.

Birman, Joel (1986). Feitiço e feiticeiro no pacto com o diabo. In: Mal-estar na atualidade. Rio de Janeiro: Civilização Brasileira, 1999.

Dionísios desencantados. In: Inem, C.L. e Acselrad, G. (orgs.). Drogas: uma visão contemporânea. Rio de Janeiro: Imago, 1993.

Bittencourt, Lígia. Algumas considerações sobre a neurose e a psicose nas toxicomanias. In: Inem, C.L. e Acselrad, G. (orgs.). Drogas: uma visão contemporânea. Op. cit.

Freud, Sigmund (1916-1917). Die Wege der Symptombildung. In: Stgb., v. I, Conferência 23, p. 350-66. (Os caminhos da formação dos sintomas. In: ESB. Rio de Janeiro: Imago, 1969. v. XVI).

(1917). Trauer und Melancholie. In: Stgb. Op. cit., 1972, v. III. (Luto e melancolia. In: ESB., op. cit. v. XIV).

(1924). Der Realitätsverlust bei Neurose und Psychose. In: Stdgb. Op. cit., 1972, v. III. (A perda da realidade na neurose e na psicose. In: ESB. Op. cit. v. XIX).

(1926). Hemmung, Symptom und Angst. In: Stdgb. Op. cit., 1972, v. VI. (Inibição, sintoma e angústia. In: ESB. Op. cit. v. XIX).

(1927). Die Zukunft einer Illusion. In: Stdgb. Op. cit., 1974. v. IX. (O futuro de uma ilusão. In: ESB. Op. cit. v. XX).

(1930). Das Unbehagen in der Kultur. In: Stdgb. Op. cit., 1974. v. IX. (O malestar na civilização. In: ESB. Op. cit., 1960, v. XXI).

Grossi, Fernando Teixeira e NogueIRA, Cristina Sandra Pinelli. O social e as novas formas do sintoma: as toxicomanias. In: Bentes, Lenita e Gomes, Ronaldo Fabião (orgs.). O brilho da (in)felicidade. Rio de Janeiro: Contra Capa, 1998, p. 91-8.

Lacan, Jacques (1966). De nos antécedents. In: Écrits. Paris: Seuil, p. 65-72. (De nossos antecedentes. In: Escritos. Rio de Janeiro: Jorge Zahar, 1998, p. 69-76. 


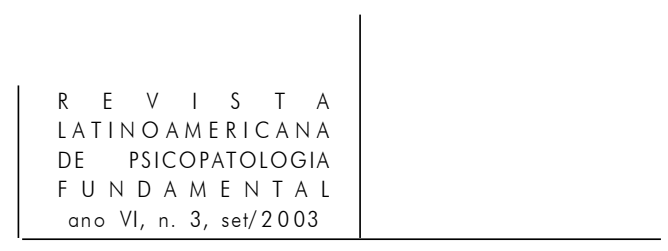

(1969-1970). Le séminaire. Livre XVII. L'envers de la psychanalyse. Paris: Seuil, 1991. (O seminário. Livro 17. O avesso da psicanálise. Rio de Janeiro: Jorge Zahar, 1992).

Le savoir du psychanalyste. Inédito, 1971-1972.

La troisième. Inédito, 1974.

Télévision. Paris: Seuil, 1974a.

Melman, Charles. Alcoolismo, delinqüência, toxicomania: uma outra forma de gozar. São Paulo: Escuta, 1992.

Paskvan, E. De la monotonia a la diversidad. Pharmakon, Buenos Aires, n. 2, 1994.

Poulichet, Sylvie. Toxicomanies et psychanalyse - les narcoses du désir. Paris: PUF, 1987.

Rabinovich, Diana. Une hystérie “démélancolisée”. Ornicar? Revue du Champ freudien, n. 28, p. 112-6, printemps 1984.

Santiago, Jésus. Toxicomania e perversão. In: Inem, C.L. e Acselrad, G. (orgs.). Drogas: uma visão contemporânea. Rio de Janeiro: Imago, 1993.

A droga do toxicômano - uma parceria cínica na era da ciência. Rio de Janeiro: Jorge Zahar, 2000.

Vigano, Carlos. Saúde Mental: psiquiatria e psicanálise. Belo Horizonte: Instituto de Saúde Mental/Associação Mineira de Psiquiatria, 1997.

\section{Resumos}

Partiendo de una lectura basada en cuatro autores brasileños, este trabajo levanta problemas y verifica posiciones teóricas sobre el fenómeno toxicómano y formula la hipótesis de que es posible, con el discurso del analista, en cierto contexto y a partir de ciertas condiciones, considerar la toxicomanía como equivalente al síntoma en el discurso de la histérica lo que abre vías para la construcción de una clínica donde prevalezca la apuesta en el deseo del analista.

Al retomar las referencias freudianas en cuanto a la equivalencia de la droga con el discurso religioso y sus funciones de entorpecimiento, se verifica una posible sustentación metafórica, necesaria para cualquier formación de síntoma. Por otro lado, al retomar las referencias de Lacan con relación al discurso capitalista como el discurso del amo contemporáneo, la cuestión es sostener la posibilidad de que la droga haga obstáculo al libre funcionamiento del goce del amo en ese discurso.

Palabras clave: Toxicomanía, síntoma, discursos, histeria, deseo

Partant de la lecture de quatre auteurs brésiliens, ce travail discute et vérifie les positions théoriques autour du phénomène de la toxicomanie, et propose l'hypothèse selon laquelle il est possible, avec le discours de l'analyste, dans un certain contexte 


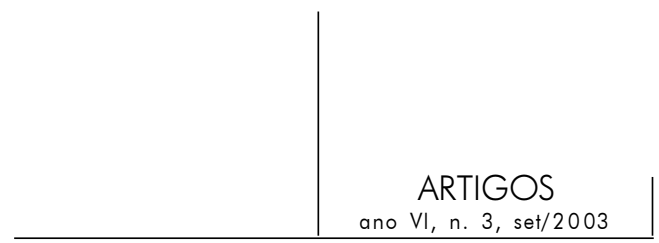

et à certaines conditions, d'établir une équivalence entre la toxicomanie et le symptôme dans le discours de l'hystérique. Ceci ouvre des voies pour la construction d'une clinique dans laquelle prévaut le pari sur le désir de l'analyste.

D’un côté, les références freudiennes quant à l'équivalence des drogues avec le discours religieux et ses fonctions de torpeur permettent de pointer une métaphorisation, nécessaire à n'importe quelle formation de symptômes. De l'autre, reprenant les références de Lacan quant au discours du capitaliste comme le discours du maître contemporain, la question est d'assurer la possibilité que la drogue se constitue en tant qu'obstacle au libre fonctionnement de la jouissance du maître dans ce discours.

Mots clés: Toxicomanie, symptôme, discours, hystérie, désir

Based on four Brazilian authors, this article discusses theoretical principles of the phenomenon of drug use and presents the hypothesis that, with the analyst's discourse, in certain contexts and under certain conditions, drug addiction could be seen as equivalent to the symptom in the hysterical discourse. This approach could open up new paths for clinical work where the analyst's desire could prevail.

Based on references by Freud relating drug use with the religious discourse and its narcotic functions, one can detect a possible metaphorical basis, necessary for the formation of any symptom. In addition, references by Lacan on the capitalist discourse as the contemporary discourse of the master bring up the possibility that drug addiction serves as an obstacle to the free jouissance of the master in this discourse.

Key words: Drug addiction, symptom, discourse, hysteria, desire

Versão inicial recebida em junho de 2003

Aprovado para publicação em agosto de 2003 